\title{
ANÁLISE TEXTUAL DISCURSIVA COMO CONSTITUINTE DE UM PROCESSO DE COMUNICAÇÃO
}

\section{THE DISCURSIVE TEXTUAL ANALYSIS AS A CONSTITUENT OF A COMMUNICATION PROCESS}

\author{
Fábio Peres Gonçalves ${ }^{1}$
}

\begin{abstract}
Resumo: A elucidação de características epistemológicas associadas à Análise Textual Discursiva (ATD) tem se constituído como objeto de estudo. Neste artigo, é retomada a defesa de que a ATD se afasta da tese relativista. Assim sendo, na qualidade de um procedimento analítico, ela também precisa alinhar-se a pressupostos teóricos que igualmente se oponham ao relativismo. Reconhecem-se, no aporte teórico do renomado educador brasileiro Paulo Freire, características que o distanciam do relativismo. Com isso, apresentam-se como objetivos do trabalho: i) analisar, na forma de uma metáfora, a comunicação na ATD com base nas contribuições desse autor em sua obra Extensão ou Comunicação?; ii) caracterizar o potencial pedagógico do exercício da ATD em pesquisas desenvolvidas em parceria no contexto da formação inicial de professores, quando articulada aos pressupostos teóricos de Freire. Nisso está subjacente a compreensão de que pressupostos teóricos assumidos explícita ou implicitamente na pesquisa não obrigatoriamente se restringem a auxiliar nos processos de unitarização, categorização e construção de metatextos, uma vez que podem influenciar, por exemplo, no próprio modo de desenvolvimento da análise.
\end{abstract}

Palavras-chave: Análise de dados; Formação de professores; Paulo Freire.

Abstract: Ellucidation of epistemological characteristics associated with the Discursive Textual Analysis has been an object of study. This paper defends that the Discursive Textual Analysis moves away from the relativist thesis. Therefore, as an analytical procedure, it needs to align with theoretical assumptions that also oppose to relativism. Theoretical contributions given by the renowned Brazilian educator Paulo Freire have shown characteristics that distance them from relativism. Thus, this study aims to: i) to analyze, as a metaphor, the communication in the Discursive Textual Analysis based on the author's belief in his study "Extension or Communication?"; and ii) to characterize the pedagogical potential of the exercise of the Discursive Textual Analysis in studies developed in a partnership with preservice teacher education programs articulated with Freire's theoretical assumptions. It underlies the understanding that theoretical assumptions explicitly or implicitly assumed by research are not necessarily restricted as an auxiliary in the processes of unitization, categorization and construction of metatexts, since they can influence, for example, the development of the analysis.

Keywords: Data analysis; Teacher training; Paulo Freire.

\section{Introdução}

A presença do relativismo na pesquisa em Ciências Humanas tem sido alvo de críticas (AMORIM, 2003). A defesa de um pluralismo teórico-metodológico neste campo não precisa obrigatoriamente confundir-se com uma espécie de "vale-tudo"

\footnotetext{
${ }^{1}$ Doutor em Educação Científica e Tecnológica pela Universidade Federal de Santa Catarina (UFSC). Docente no Departamento de Química da UFSC, Florianópolis, Santa Catarina, Brasil. E-mail: fabio.pg@ufsc.br
} 
(DELIZOICOV, 2004). Caso contrário, no caso da pesquisa educacional, pode-se ter, entre outras implicações, o empobrecimento tanto dos conteúdos escolares quanto do que se constitui em cultura (DUARTE, 2006).

$\mathrm{Na}$ qualidade de um procedimento de análise qualitativa utilizada em pesquisas em Ciências Humanas (aplicadas), a Análise Textual Discursiva (ATD) não se alija do debate concernente ao relativismo (GONÇALVES, 2020). Aliás, como chamam a atenção Santos e Greca (2013), as metodologias não se reduzem a puros procedimentos a serem executados nas investigações. Assim como as referências teóricas, elas são caracterizadas por premissas epistemológicas. Para as autoras, as pesquisas divulgadas na literatura nem sempre são congruentes na associação entre metodologia e os interlocutores teóricos, por exemplo. Um dos efeitos dessa incoerência pode ser a produção de um conhecimento cuja qualidade é bastante questionável.

Nessa direção, se tem sinalizado que a ATD se aproxima de premissas epistemológicas do conhecido educador brasileiro Paulo Freire, uma vez que em ambos é possível encontrar uma crítica a ideias que se harmonizam com o relativismo (GONÇALVES, 2020). Na literatura, localizam-se trabalhos que se ocupam de discutir de maneira sistematizada a aproximação entre a ATD e aspectos da obra de Paulo Freire, particularmente o processo de investigação temática.

Reconhecidamente, a ATD e a investigação temática são compostas de etapas. A primeira constitui-se em um procedimento de análise, enquanto a segunda, em um processo que permite a obtenção de temas geradores e dos conteúdos programáticos. Torres et al., (2008) discorreram a respeito de um processo de obtenção de temas, via investigação temática, associado à ATD. Os autores associam a primeira etapa do processo de investigação temática proposto por Freire (2005), qual seja, o levantamento preliminar, à primeira etapa da ATD (unitarização). Já a análise das situações/escolha das codificações e diálogos descodificadores, na qualidade de etapas da investigação temática, foram articuladas à categorização (segunda etapa da ATD). Por fim, as etapas de redução temática e sala de aula foram vinculadas à etapa de comunicação (terceira etapa da ATD). Torres et al., (2008) também defendem que a ATD pode estar presente em cada etapa da investigação temática. Nesta significação, em Milli, Solino e Gehlen (2018), encontram-se contribuições concernentes a articulações teórico-metodológicas entre a ATD e a primeira etapa da investigação temática. Um dos aspectos sustentados pelos autores é que a referida etapa não se encerra na obtenção fortuita de informações de certa realidade. Associada a isto, está a defesa de que o levantamento preliminar da 
realidade não pode depauperar-se em momento mecânico, pois isso reduziria o seu potencial humanístico.

Em face do exposto, é retomada a tese de que a ATD se opõe ao relativismo e, de forma coerente, precisa associar-se a pressupostos teóricos - explícitos ou tácitos que se distanciem igualmente dessa posição epistemológica (GONÇALVES, 2020). Essa é uma discussão não realizada explicitamente, nem nos trabalhos supracitados, que vinculam teórico-metodologicamente as ideias de Paulo Freire à ATD, nem naqueles que realizam discussões de natureza filosófica a respeito desse procedimento, como os de Sousa, Galiazzi e Schmidt (2016) e Sousa e Galiazzi (2016). É uma discussão desenvolvida de tal sorte a não abrandar o potencial humanístico da ATD, de modo análogo ao que argumentam Milli, Solino e Gehlen (2018) para as etapas da investigação temática proposta por Paulo Freire.

Em harmonia com isso, os objetivos do trabalho são: i) analisar, na forma de uma metáfora, a comunicação na ATD com base nas contribuições de Paulo Freire em sua obra Extensão ou Comunicação? (FREIRE, 1977); ii) caracterizar o potencial pedagógico do exercício da ATD em pesquisas desenvolvidas em parceria no contexto da formação inicial de professores, quando articulada aos pressupostos teóricos de Freire. Assim, além de expor, a seguir, argumentos defendidos ultimamente (GONÇALVES, 2020) da oposição da ATD ao relativismo, advoga-se que o referencial teórico de Paulo Freire, particularmente a obra supracitada, do mesmo modo se distancia do relativismo e fornece uma base para construção de um entendimento da ATD como constituinte de um processo de comunicação. Adicionalmente, apresenta-se um exemplo de como o entendimento da ATD como constituinte de um processo de comunicação poderá influenciar a maneira de conduzir a análise das informações qualitativas em pesquisas que a adotam.

\section{A Análise Textual Discursiva e a objeção ao relativismo}

Recentemente, defendemos (GONÇALVES, 2020) que os pressupostos teóricos da ATD se distanciam do relativismo. Essa posição filosófica exprime que a verdade é relativa ao contexto e, de forma reconhecida, guarda em sua formulação uma contradição: se a verdade é relativa, então também é aquela do relativismo.

Além dessa incoerência, há outros limites apontados no relativismo. Boudon (2010), por exemplo, acena para a perturbação moral e política que o relativismo pode 
carregar consigo. Para o autor, se a verdade estivesse vinculada ao contexto, então, não se poderiam contestar, por exemplo, discursos em favor da necessidade da pobreza que assola a população mundial.

Está na gênese da ATD o reconhecimento de uma realidade que independe do pesquisador - o que, inversamente, pode associar-se à tese relativista, entendendo a realidade como uma pura construção social -, bem como da necessidade de um compromisso político do pesquisador que identifica a premência da superação de determinados discursos:

Finalmente, a partir da convicção da importância de integrar qualidade formal e política, emerge da análise a possibilidade de transformação das realidades investigadas. As aprendizagens concretizadas, expressas nos metatextos, organizados em torno de teses e argumentos do pesquisador, podem constituir-se em formas de intervenção nos discursos nos quais os textos submetidos à análise se inserem. Nisso situa-se a qualidade política das análises e de seus produtos.

Assim, uma ATD rigorosa pode garantir a qualidade formal dos resultados da pesquisa. A qualidade política, entretanto, depende dos pressupostos assumidos pelo pesquisador em seu trabalho, especialmente o assumir como sujeito histórico, capaz de intervir nos discursos no sentido de sua reconstrução.

[...] é um modo de intervir na realidade, assumindo-se o pesquisador como sujeito histórico, capaz de participar na reconstrução de discursos existentes (MORAES; GALIAZZI, 2007, p. 136-137).

Do exposto, apreende-se a oposição da ATD a um relativismo que, ao valorizar a pluralidade discursiva, não tem o compromisso de enfrentar as desigualdades que sustentam certa pluralidade. É um enfretamento do qual o relativismo foge.

Cumpre registrar o que não significa a aversão da ATD ao relativismo. Não se trata, obviamente, de uma adesão ao dogmatismo - como uma posição epistemológica, assim como o relativismo, ao problema da possibilidade do conhecimento: será o sujeito realmente capaz de apreender o objeto? -, para o qual os objetos do conhecimento estariam dados. Nem se trata de enaltecer um realismo ingênuo, na medida em que se admite uma realidade independente do sujeito do conhecimento. Para Hessen (2003, p. 74), o realismo ingênuo "não é ainda determinado por nenhuma reflexão epistemológica e o problema sujeito-objeto ainda não surgiu claramente”. Nem se trata de negligenciar a relação entre palavra e contexto, como quem deseja negar a variabilidade de sentidos que uma palavra pode assumir.

Como alternativa à resposta do dogmatismo e do relativismo ao problema da possibilidade do conhecimento, o criticismo advoga em favor da existência da verdade, ao mesmo tempo em que coloca em xeque qualquer conhecimento determinado 
(HESSEN, 2003). Em análise preliminar, apresentamos (GONÇALVES, 2020) a interpretação de que é do criticismo que a ATD parece aproximar-se.

Já em relação ao realismo, ainda que este traga uma resposta para outro problema que não o da possibilidade de conhecimento, qual seja, o da essência do conhecimento, não é incoerente que os defensores do relativismo desacreditem em uma realidade independente do sujeito.

Moraes e Galiazzi (2007), ao concordarem com a necessidade de considerar-se o contexto na interpretação do corpus de pesquisa, não remetem ao relativismo. Aliás, a discussão sobre a relação entre palavra e contexto aparece no próprio âmbito da Filosofia da Linguagem. Bakhtin (2004, p. 106), por exemplo, expõe essa relação: “o sentido da palavra é totalmente determinado por um contexto. De fato, há tantas significações possíveis quantos contextos possíveis". Bakhtin é reconhecidamente um crítico ao relativismo (DUARTE, 2006; AMORIM, 2003).

A crítica ao relativismo na ATD está em sintonia com discussões atuais de Sousa, Galiazzi e Schmidt (2016) e de Sousa e Galiazzi (2016) ao explorarem-na sob a hermenêutica filosófica de Hans-Georg Gadamer. Ainda que esses autores não tragam considerações explícitas concernentes ao relativismo na ATD, a fenomenologia hermenêutica de Gadamer tem sido caracterizada como discordante da tese relativista, uma vez que, entre outros aspectos, buscou enfrentar um anarquismo hermenêutico, com critérios para diferenciar interpretações adequadas e inadequadas (SILVA, 2008).

Em suma, o distanciamento da ATD da tese relativista impõe alerta à escolha dos referenciais teóricos, de modo a não incorrer em uma incongruência, de natureza epistemológica, entre os interlocutores teóricos e a metodologia da pesquisa, como destacam Santos e Greca (2013). Com isso, não se reduz a ATD a um puro procedimento.

\section{A análise textual discursiva: extensão ou comunicação?}

A seguir, ao considerar-se a discussão sobre o relativismo, são descritas as etapas da ATD, para posteriormente caracterizá-las, em seu conjunto, como constituintes de um processo de comunicação. Para tanto, também nos apoiaremos nas contribuições de Freire em sua acepção de comunicação no ato educativo. 


\subsection{As etapas da análise textual discursiva}

Moraes (2003) estabelece originalmente a ATD como procedimento de análise de informações qualitativas constituído de etapas: desmontagem de textos (unitarização), categorização e captação do novo emergente (comunicação). Na sequência, sistematizaremos cada uma das etapas para que posteriormente se possa endossar o argumento de como sua execução na pesquisa pode ser constituinte de um processo de comunicação.

\subsubsection{Unitarização: "cada ordem traz uma semente de desordem"2}

Esta etapa concretiza-se a partir da disponibilização inicial do corpus, caracterizado por produções textuais diversas (derivadas da transcrição de entrevistas, de respostas a questionários, de documentos oficiais, etc.). A leitura inicial do corpus já é permeada por pressupostos teóricos explícitos ou tácitos, assumidos pela equipe de pesquisa ou por seus integrantes individualmente - considera-se aqui a pesquisa realizada de forma coletiva, mas é sabido que a investigação também pode ser conduzida individualmente. De forma especial, neste trabalho de pesquisa coletiva, se reconhecem as múltiplas leituras que podem ser derivadas de um mesmo corpus. Nisso está subentendida uma compreensão do processo de leitura que se inicia na unitarização.

$\mathrm{O}$ ato de ler precisa considerar a relação entre palavra e contexto, como já destacado com base em Bakhtin (2004), e seguramente isto não pode ser confundido com o relativismo criticado previamente. Amorim (2003) ensina que a filosofia da linguagem de Bakhtin se opõe ao relativismo, uma vez que o combate à ideia de transparência do texto não implica, na compreensão deste teórico, a rejeição ao trabalho de objetivação e conceituação. Inversamente, o trabalho de objetivação e conceituação é caracterizado por uma tensão reconhecida por Bakhtin, mas desprezada pela postura relativista. Em outras palavras, como destacam Moraes e Galiazzi (2007, p. 57), o contexto precisa ser considerado neste processo de unitarização: "Suas leituras [do pesquisador], mesmo que exijam seu envolvimento ativo e participativo, são condicionadas pelo contexto e pelos discursos em que textos analisados se enquadram. Interpretações rigorosas e válidas requerem que se associe de forma competente o texto

\footnotetext{
2 Trecho de Lavoura arcaica (NASSAR, 1989, p. 158).
} 
e o contexto". Portanto, não se trata de um "vale-tudo" interpretativo ao consideraremse as múltiplas possibilidades de leitura de textos.

Como um procedimento, a unitarização implica a fragmentação dos textos constituintes do corpus em unidades de análise (unidades de sentido ou unidades de significado). Avalia-se que a análise dessas unidades colabora para responder a questão de pesquisa ou atingir os objetivos. Essas unidades de análise podem ser organizadas ${ }^{3}$ inicialmente de acordo com a criatividade do grupo de pesquisa - uma criatividade que pode relacionar-se, inclusive, com a mediação das tecnologias digitais da informação e comunicação. Como exemplo, tem-se a utilização do software Atlas.ti (ARIZA et al., 2015). A interpretação presente nessa fragmentação possibilita não somente a extração das unidades de análise, cujo exame se relaciona com objetivos/questão de pesquisa, mas também a construção de textos mais elaborados, a serem utilizados na produção dos metatextos no processo de comunicação, descrito a seguir. Essa etapa, assim como as demais, não se caracteriza por uma linearidade na sua execução. A dinâmica recursiva e social de leitura e escrita influencia o modo como a unitarização é promovida.

Do pressuposto de que "cada ordem traz uma semente de desordem", pode-se afirmar que, da ordem do corpus à desordem proporcionada pela dilaceração dos textos, se pode viabilizar uma impregnação das informações qualitativas. Como defende Moraes (2003), é a partir dessa desordem e impregnação que se procura construir uma nova ordem. É esse o objetivo da segunda etapa da ATD.

\subsubsection{Categorização: "só se une se desunindo"4}

A partir da desordem estabelecida na unitarização, inicia-se um processo de elaboração de uma nova organização por meio da construção de categorias. Estas podem caracterizar-se como a priori, emergentes ou mistas.

As primeiras derivam de um referencial teórico explícito da pesquisa e, assim como as demais, representam um processo de natureza classificatória que agrupa unidades de análise de acordo com as suas semelhanças. Antes mesmo de iniciar a análise, têm-se à disposição as categorias nas quais se pretende enquadrar as unidades de análise.

\footnotetext{
${ }^{3}$ Por exemplo, Moraes (2003) sugere a utilização de códigos para identificar a origem das unidades de análise.

${ }^{4}$ Trecho de Lavoura arcaica (NASSAR, 1989, p. 162).
} 
Categorias engendradas a partir da desordem da unitarização são denominadas de emergentes. Obviamente, não se trata de categorias produzidas em um fantasioso vácuo teórico, como pode sugerir uma interpretação apressada. A notoriedade da discussão filosófica sobre a não neutralidade do sujeito do conhecimento dispensa uma discussão nessa direção. Endossando o exposto, Moraes e Galiazzi (2007, p. 127) destacam que "a emergência [...] não é um brotar de algo, mas uma reconstrução do pesquisador a partir de compreensões teóricas já existentes". Ademais, cumpre registrar que essa discussão sobre a não neutralidade não pode confundir-se com aquela do relativismo.

As categorias mistas combinam as predeterminadas com as emergentes. É possível, por exemplo, ter categorias a priori e subcategorias emergentes. Essa aproximação de processos de categorização pode ser uma forma de enfrentar limites que uma ou outra opção traz consigo. Por exemplo, a escolha de categorias antes da análise pode ter como consequência a não classificação de unidades de análise, ainda que importantes, pois aquelas podem ser limitadas para abrigar a pluralidade de sentidos representada pelas unidades de análise.

O processo de categorização na ATD não atende ao princípio de exclusão mútua, de tal sorte que uma mesma unidade de análise pode ser incluída em mais de uma categoria (MORAES, 2003). Isso pode contribuir para o estabelecimento de relação entre as categorias e minimizar a fragmentação decorrente da análise.

Dada uma nova ordem derivada do agrupamento dos fragmentos resultantes da desunião inicial dos textos constituintes do corpus - só se une se desunindo -, é o momento da terceira etapa da ATD.

\subsubsection{Comunicação: "toda palavra é uma semente"5}

Nesta etapa, são construídos metatextos descritivos e interpretativos a partir da estrutura das categorias e subcategorias. Ainda que na descrição já esteja tácita uma interpretação, um investimento na segunda significa um movimento em direção a uma compreensão mais aprofundada, sem se restringir ao que está manifesto nas unidades de análise. Na descrição e interpretação, é importante expor as ideias de quem analisa, bem como as unidades de análise. Para Moraes e Galiazzi (2007), a validade das categorias e dos argumentos construídos na análise pode ser favorecida pela exposição das unidades

\footnotetext{
5 Trecho de Lavoura arcaica (NASSAR, 1989, p. 165).
} 
de análise, de modo que um suposto anarquismo interpretativo das informações qualitativas, em sintonia com a tese relativista, é combatido.

A interlocução teórica explícita, independentemente da existência de um referencial teórico previamente selecionado, é fundamental para reforçar posicionamentos interpretativos, sem com isto suprimir os argumentos originais da equipe de pesquisadores, registrando-se os avanços da investigação para o campo no qual se insere.

A metáfora da palavra compartilhada, nesta etapa, como uma semente é um reconhecimento do caráter lacunar da análise, que implica desdobramentos para outros trabalhos e que se apresenta humildemente para o leitor.

\subsection{A comunicação em detrimento da extensão}

Em sua obra Extensão ou Comunicação?, Freire (1977), em parte, analisa o trabalho do profissional extensionista da agronomia, quando este pode ter a intenção, por meio de sua prática, de substituir os conhecimentos das pessoas para quem suas ações se destinam. Nisso é questionável o entendimento de extensão - do ponto de vista semântico e gnosiológico -, como o de educação a ele associado

Para o autor, a extensão pode ser compreendida como uma suposta transmissão de conhecimentos às pessoas que passivamente os acolhem. Nisso subjaz um desrespeito pelos conhecimentos daqueles a quem são dedicadas as práticas educativas. A valorização desses conhecimentos em Freire (1977), por outro lado, não é concebida como uma adesão à ideia de que as pessoas, ao terem conhecimentos particulares em dado contexto, não necessitam aprender outros conhecimentos, entre os quais, aqueles sistematizados, próprios das práticas educativas. Do contrário, se estaria enaltecendo um relativismo. Assim como na ATD, nas ideias de Paulo Freire, também é possível localizar o distanciamento desse posicionamento epistemológico. Como já argumentamos em outra oportunidade (GONÇALVES, 2020), em alguma medida, essa crítica ao relativismo aproxima o procedimento analítico em discussão do referencial de Paulo Freire. A seguir, um exemplo de trecho em que é possível apreender uma crítica do autor à posição relativista:

Ao contrário, educar e educar-se, na prática da liberdade, é tarefa daqueles que sabem que pouco sabem - por isto sabem que sabem algo e podem assim chegar a saber mais - em diálogo com aqueles que, quase sempre, pensam que nada sabem, para que estes, transformando o seu pensar que nada sabem em saber que pouco sabem, possam igualmente saber mais (FREIRE, 1977, p. 25). 
Além do julgamento em discussão, depreende-se do exposto por Freire (1977) uma depreciação da ideia de que, no processo educativo, o/a aprendiz se reduz a um objeto da incidência dos conhecimentos de outrem. Como diz o próprio autor: "é necessário que na situação educativa educador e educando assumam papel de sujeitos cognoscentes, mediatizados pelo objeto cognoscível que buscam conhecer” (FREIRE, 1977, p. 28). Aí reside outra avaliação da extensão, que não reconhece o binômio educador/a-educando/a - terminologia utilizada por Freire (1977).

Esse binômio, de outra parte, é constituinte do que Freire (1977) defende como comunicação $^{6}$, em que não há a passividade característica da extensão, na condição de quem aprende como um depósito de conhecimentos. Nas palavras do autor:

O sujeito pensante não pode pensar sozinho; não pode pensar sem a coparticipação de outros sujeitos do ato de pensar sobre o objeto. Não há um "penso", mas um "pensamos". É o "pensamos" que estabelece o "penso" e não o contrário.

Esta co-participação dos sujeitos no ato de pensar se dá na comunicação. O objeto, por isso mesmo, não é a incidência terminativa do pensamento de um sujeito, mas o mediatizador da comunicação.

Daí que, como conteúdo da comunicação, não possa ser comunicado de um sujeito a outro.

Se o objeto do pensamento fosse um puro comunicado, não seria um significado significante mediador dos sujeitos.

Se o sujeito "A" não pode ter no objeto o termo de seu pensamento, uma vez que este é a mediação entre ele e o sujeito "B", em comunicação, não pode igualmente transformar o sujeito " $\mathrm{B}$ " em incidência depositária do conteúdo do objeto sobre o qual pensa. Se assim fosse - e quando assim é -, não haveria nem a comunicação. Simplesmente um sujeito estaria (ou está) transformando o outro em paciente de seus comunicados ${ }^{1}$.

A comunicação, pelo contrário, implica numa reciprocidade que não pode ser rompida.

Por isto não é possível compreender o pensamento fora de sua dupla função: cogniscitiva e comunicativa.

Esta função, por sua vez, não é extensão do conteúdo significante do significado, objeto do pensar e do conhecer.

Comunicar é comunicar-se em torno do significado significante.

Desta forma, na comunicação, não há sujeitos passivos. Os sujeitos cointencionados ao objeto de seu pensar se comunicam seu conteúdo.

O que caracteriza a comunicação enquanto este comunicar comunicando-se, é que ela é diálogo, assim como o diálogo é comunicativo (FREIRE, 1977, p. 66-67).

Esta caracterização da comunicação sugere reflexões, por exemplo, a respeito da relação entre pesquisadores em ensino de ciências/formadores de professores e estudantes de licenciatura que participam de investigações em parceria com os primeiros, de maneira análoga àquelas reflexões expostas por Freire (1977) acerca da relação entre o profissional de agronomia na relação com o/a camponês/camponesa. Se

\footnotetext{
${ }^{6}$ Freire (1977) fundamenta-se em ideias do filósofo Eduardo Nicol para destacar que, além das relações gnosiológica, lógica e histórica, constitutivas do conhecimento, há a relação dialógica. Assim, o educador brasileiro defende que, além do sujeito pensante e de um objeto pensado, há a comunicação.
} 
não é admissível a extensão do pensado do agrônomo profissional ao/à camponês/camponesa, também não é a dos pesquisadores em ensino de ciências, na qualidade igualmente de formadores de professores, a estudantes de licenciatura iniciantes em projetos de pesquisa. Freire (1977, p. 68) complementa: "Vê-se assim que a busca do conhecimento que se reduz à pura relação sujeito cognoscente-objeto cognoscível, rompendo com a 'estrutura dialógica' do conhecimento, está equivocada, por maior que seja sua tradição". Nesta direção, menos admissível ainda é esses estudantes de licenciatura que se inserem na pesquisa serem tratados como desprovidos de "pré-requisitos" para o diálogo com pesquisadores profissionais no momento de analisar as informações qualitativas, como quem diz que neles está impressa uma incapacidade para o ato comunicativo.

No entendimento de educação como ato comunicativo, na acepção de Freire (1977), cabem as indagações:

Quem, entre os sujeitos cognoscentes, propõe os temas básicos que serão objeto da ação cogniscitiva?

Se a educação, como situação gnosiológica, tem, na relação dialógica, sua essência, visto que, sem ela, desapareceria a co-intencionalidade dos sujeitos ao objeto cognoscível, quando começa esta relação? (FREIRE, 1977, p. 86).

Para Freire (1977), a definição do que será estudado está na gênese do diálogo entre os sujeitos cognoscentes que constituem o ato educativo. Freire (1977) propõe que a escolha do que se vai ensinar inicie por meio da investigação do "tema gerador", de maneira que "pesquisa do 'tema gerador' e educação como situação gnosiológica são momentos de um mesmo processo" (FREIRE, 1977, p. 88). Ainda que não constitua escopo deste trabalho aprofundar a discussão sobre a delimitação dos temas geradores, cumpre registrar que a investigação temática proposta por Freire (2005) no âmbito da educação não formal é um processo por meio do qual se obtêm os temas geradores. Esse processo foi sistematizado por Delizoicov (1982) nas seguintes etapas, considerando já a educação formal: a) levantamento preliminar; b) análise das situações e escolha das codificações; c) diálogos descodificadores; d) redução temática; e e) desenvolvimento em sala de aula. Nesse sentido, retoma-se Freire (1977, p. 88): "Daí que o quefazer educativo [...] seja inteiramente contrário da ação puramente extensiva dos conteúdos escolhidos por um de seus polos". Esta compreensão da educação como processo de comunicação, quando tomada metaforicamente para refletir sobre a pesquisa em parceria entre pesquisadores em ensino de ciências/formadores de professores e estudantes de licenciatura, por exemplo, sugere que o diálogo inicia na definição do que 
será investigado - portanto, antes mesmo da realização da análise das informações qualitativas. Não caberia a doação de uma proposta de pesquisa dos primeiros àqueles estudantes de licenciatura que se iniciam na pesquisa, tampouco a ideia de um mero treinamento para conduzir o exame de informações qualitativas coletadas mecanicamente.

Sem negligenciar os limites intrínsecos ao exercício metafórico desenvolvido, advoga-se em favor do seu potencial heurístico para refletir sobre a pesquisa em parceria entre pesquisadores em ensino de ciências/formadores de professores e estudantes de licenciatura, mais particularmente, a respeito da utilização da ATD nessas pesquisas.

\subsection{A análise textual discursiva é comunicação: possibilidade para pesquisa em parceria entre professores na formação inicial}

É impossível consentir com a atuação superficial de certos participantes de trabalhos de pesquisa quando se tenta reduzi-los, por exemplo, a simples transcritores de entrevistas gravadas em áudio, aplicadores de questionários e coletores de documentos destinados aos membros mais experientes da investigação, que estariam responsáveis por envolver-se com o trabalho de realização das análises qualitativas e, posteriormente, estender esses resultados àqueles que coletaram informações qualitativas e deram um tratamento inicial para a constituição do corpus a ser examinado. Isso seria como dizer que é papel de "A" transferir para " $B$ " conhecimentos sistematizados por meio da análise, ou então, que é reservada à "A" a oportunidade de envolver-se efetivamente com a construção do conhecimento. Assim, ficam à margem da construção do conhecimento aqueles que contemplam os conhecimentos doados. Peremptoriamente, a ATD, na qualidade de processo de comunicação, rejeita essa ação.

Para Freire (1996), a pesquisa é constituinte da prática docente. A ideia de um professor como pesquisador, tão propalada na literatura, também encontra uma interpretação na obra do renomado educador brasileiro. Ainda em sua obra Pedagogia da Autonomia: saberes necessários à prática educativa, Freire (1996) menciona explicitamente a ideia de professor como pesquisador. Uma compreensão de como a pesquisa pode ser entendida na docência foi antecipada em outro contexto de discussão:

Para muitos de nós, a realidade concreta de uma certa área se reduz a conjunto de materiais ou de fatos cuja existência ou não, de nosso ponto de vista, importa constatar. Para mim, a realidade concreta é algo mais que fatos ou dados tomados mais ou menos em si mesmos. Ela é todos esses fatos e 
todos esses dados e mais a percepção que deles esteja tendo a população envolvida. Assim, a realidade concreta se dá a mim na relação dialética entre objetividade e subjetividade.

[...] Dizer que a participação direta, a ingerência dos grupos [...] no processo de pesquisa altera a "pureza" dos resultados implica na defesa da redução daqueles grupos a puros objetos da ação pesquisadora de que, em consequência, os únicos sujeitos são os pesquisadores profissionais. $\mathrm{Na}$ perspectiva libertadora em que me situo pelo contrário, a pesquisa como ato de conhecimento tem como sujeitos cognoscentes, de um lado, os pesquisadores profissionais, de outro, os grupos [...] e, como objeto a ser desvelado, a realidade concreta (FREIRE, 1981, p. 35).

O expresso por Freire (1981) pode sustentar um entendimento sobre o professor como pesquisador, em geral, e acerca da pesquisa em parceria na formação inicial de professores, em particular. Apoiados nesta compreensão de pesquisa e no referencial teórico de Paulo Freire, disseminamos, em trabalho recente, uma pesquisa em parceria entre formador e duas licenciandas em Química (SILVEIRA; PIAIA; GONÇALVES, 2020). Destaca-se esse trabalho como um exemplo de como o referencial teórico vinculado à ATD pode influenciar o próprio modo de desenvolvimento da análise, caracterizando a ATD como um processo de comunicação, ainda que se apoiando metaforicamente na acepção de Freire (1977).

Assim, ao advogar-se em favor de uma busca de coerência epistemológica entre o referencial teórico e os procedimentos analíticos adotados na pesquisa, no caso em particular, entre a ATD e os pressupostos teóricos, sejam eles explícitos ou tácitos, isso não significa reduzir o papel desses pressupostos a auxiliares na unitarização, construção de categorias de análise ou na elaboração de metatextos. Eles podem influenciar a maneira como a ATD é conduzida, inclusive, de forma a realçar a qualidade política desse procedimento analítico.

$\mathrm{Na}$ pesquisa em parceria supracitada, foram analisados os conhecimentos das licenciandas acerca de limites e potencialidade de uma proposta de abordagem temática, apoiada nos pressupostos de Freire (2005), promovida no estágio supervisionado de um curso de licenciatura em Química. O planejamento e o desenvolvimento do estágio foram registrados em um diário virtual coletivo, de autoria das licenciandas e do formador responsável pela supervisão do estágio. Além da descrição das atividades do período de observação e regência na escola, as licenciandas expressavam individualmente as suas reflexões no diário virtual coletivo. A partir disso, o formador interagia constantemente com as estagiárias por meio de registros escritos. Essa interação foi orientada por uma proposta teórico-metodológica - apoiada na definição de Freire (1977) a respeito de problematização - com momentos de explicitação dos 
conhecimentos das licenciandas e outros de apropriação de novos conhecimentos, sendo ambos mediados pela problematização (GONÇALVES; BIAGINI; GUAITA, 2019)

Além de o diário virtual coletivo ter se caracterizado como uma ferramenta formativa, ele se constituiu como corpus da pesquisa em discussão. A análise do diário virtual coletivo foi orientada pela compreensão de pesquisa supramencionada, com base em Freire (1981), possibilitando que as licenciandas participassem ativamente, em parceria com o formador, do exame das informações qualitativas por meio da ATD. Depreendeu-se do trabalho, dentre outros aspectos, que o exercício da ATD por meio da pesquisa em parceria entre formador e licenciandas foi relevante à promoção de reflexões sobre a própria prática, seja como professoras da educação básica, seja como formador de professores.

Em síntese, entende-se que a pesquisa explicitada aqui se constitui em um exemplo de como um referencial teórico assumido, que neste caso é aquele do renomado educador brasileiro Paulo Freire e que, assim como a ATD, se distancia da tese relativista, pode colaborar não somente nos processos de unitarização, construção de categorias e produção de metatextos, como também no próprio modo como a ATD pode ser caracterizada em uma pesquisa em parceria entre licenciandas e formador. $\mathrm{O}$ desenvolvimento da ATD, no contexto de pesquisa sobre a própria prática, é coerente com pressupostos da ATD, que, ao buscar uma qualidade política, como destacam Moraes e Galiazzi (2007), associada também aos pressupostos teóricos assumidos na investigação, se caracteriza por intervir em discursos e na realidade concreta. E, como ressaltou Freire (1981), constituem esta realidade as pessoas e a percepção que têm da realidade.

\section{Considerações finais}

Da discussão realizada, depreende-se que empobrece a ATD reduzi-la a um simples conjunto de procedimentos aplicados ao exame de informações qualitativas, uma vez que ela tem uma sustentação teórica que impõe a necessidade de o pesquisador harmonizá-la com seus pressupostos teóricos - explícitos ou tácitos. A essa defesa, já realizada em trabalho anterior (GONÇALVES, 2020), soma-se outra: os referenciais ou pressupostos teóricos adotados na investigação, além de favorecerem a unitarização, categorização e comunicação na ATD, podem ter implicações no próprio modo de realizar a análise. 
A forma de promover a ATD também pode endossar a tese de que ela se distancia de um relativismo pernicioso. Aceitar a ATD como um processo de extensão, como já discutido, tem implicações indesejáveis, que não condizem com a qualidade política a ela atribuída. Ademais, o exposto aqui está em sintonia com o abordado em outros trabalhos, como o de Pedruzzi et al., (2015), que é a valorização da dimensão social da ATD. Advoga-se que a aproximação entre a ATD e o referencial de Paulo Freire pode colaborar para tal valorização, bem como para realçar o potencial humanístico da ATD.

Outrossim, como possibilidade para estudos que buscam a articulação entre as ideias de Paulo Freire e a ATD, entende-se a submissão de obras do conhecido educador brasileiro a um exame para identificação de pressupostos epistemológicos presentes em sua compreensão de educação. Apesar de se considerar que a desarmonia com a tese relativista é tão manifesta em obras de Paulo Freire, é importante avançar na caracterização de seus pressupostos epistemológicos, tendo em vista auxiliar no entendimento de como suas ideias se aproximam daquelas de outros referenciais teóricos e de ferramentas metodológicas, como a ATD. Esse exame de obras de Freire pode ser conduzido com o próprio auxílio da ATD.

Com o exposto neste trabalho, não se teve a intenção de engessar um entendimento de como deve ocorrer a condução da ATD em dada especificidade, que seria aquela da pesquisa em parceria entre professores atuantes em licenciaturas e estudantes desses cursos. Entende-se que a sua utilização tem caráter mais plural, sem incorrer, todavia, em uma espécie de "vale-tudo".

\section{Referências}

AMORIM, M. A contribuição de Mikhail Bakhtin: a tripla articulação ética, estética e epistemológica. In: FREITAS, M. T; JOBIM e SOUZA, S.; KRAMER, S. Ciências Humanas e pesquisa: leituras de Mikhail Bakhtin. São Paulo: Cortez, 2003. p. 11-25.

ARIZA, L. G. A. et al. Relações entre Análise Textual Discursiva e o software ATLAS.ti em interações dialógicas. Campo Abierto, Badajoz, v. 34, n. 2, p. 105-124. 2015.

BAKHTIN, M. (Volochinov, V. N.). Marxismo e Filosofia da Linguagem: problemas fundamentais do método sociológico da ciência da linguagem. 11. ed. São Paulo: Hucitec, 2004.

BOUDON, R. O relativismo. São Paulo: Edições Loyola, 2010.

DELIZOICOV, D. Concepção Problematizadora do Ensino de Ciências na Educação

Formal. 1982. Dissertação (Mestrado em Ensino de Ciências) - Instituto de Física/ Faculdade de Educação, Universidade de São Paulo, São Paulo. 1982 
DELIZOICOV, D. Pesquisa em ensino de ciências como ciências humanas aplicadas. Caderno Brasileiro de Ensino de Física, Florianópolis, v. 21, n. 2, p. 145-175, agosto. 2004

DUARTE, N. A contradição entre universalidade da cultura humana e o esvaziamento das relações sociais: por uma educação que supere a falsa escolha entre etnocentrismo ou relativismo cultural. Educação e Pesquisa, São Paulo, v. 32, n. 3, p. 607-618, setembrodezembro,. 2006.

FREIRE, P. Extensão ou comunicação? 12. ed. Rio de Janeiro: Paz e Terra, 1977

FREIRE, P. Criando métodos de pesquisa alternativa: aprendendo a fazê-la melhor através da ação. In: BRANDÃO, C. R. Pesquisa participante. 4. ed. São Paulo: Editora Brasiliense, 1981. p. 34-41.

FREIRE, P. Pedagogia da Autonomia: saberes necessários à prática educativa. 30. ed. São Paulo: Paz e Terra, 1996.

FREIRE, P. Pedagogia do Oprimido. 40. ed. Rio de Janeiro: Paz e Terra, 2005.

GONÇALVES, F. P.; BIAGINI, B.; GUAITA, R. As transformações e as permanências de conhecimentos sobre atividades experimentais em um contexto de formação inicial de professores Química. Investigações em Ensino de Ciências, Porto Alegre, v. 24, n. 3, p. 101120, dezembro. 2019.

GONÇALVES, F. P. Considerações de natureza epistemológica acerca da análise textual discursiva. Educação, Porto Alegre, v. 43, n. 1, p. 1-12, janeiro-abril. 2020.

HESSEN, J. Teoria do conhecimento. 2. ed. São Paulo: Martins Fontes, 2003.

MILLI, J. C. L.; SOLINO, A. P.; GEHLEN, S. T. A Análise Textual Discursiva na Investigação do Tema Gerador: por onde e como começar? Investigações em Ensino de Ciências, Porto Alegre, v. 23, n. 1, p. 200-229, abril. 2018.

MORAES, R. Uma tempestade de luz: a compreensão possibilitada pela análise textual discursiva. Ciência \& Educação, Bauru, v. 9, n. 2, p. 191-211. 2003

MORAES, R.; GALIAZZI, M. do C. Análise Textual Discursiva. Ijuí: Editora Unijuí, 2007.

NASSAR, R. Lavoura arcaica. 3. ed. São Paulo: Companhia das Letras, 1989.

PEDRUZZI, A. das N et al. Análise textual discursiva: os movimentos da metodologia de pesquisa. Atos de Pesquisa em Educação, Blumenau, v. 10, n. 2, p. 584-604, maio-agosto. 2015.

SANTOS, F. M. T.; GRECA, I. M. Metodologias de pesquisa no ensino de ciências na América Latina: como pesquisamos na década de 2000. Ciência \& Educação, Bauru, v. 19, n. 1, p. 1533. 2013.

SILVA, R. S. da. O problema do relativismo em Heidegger e Gadamer. Investigaciones fenomenológicas, Madrid, n. 6, p. 283-297. 2008.

SILVEIRA, R. A. da; PIAIA, L.; GONÇALVES, F. P. A problematização da abordagem temática na formação inicial de professores de química. Química Nova, São Paulo, v. 43, n. 10, p. 1529-1539. 2020. 
SOUSA, R. S. de, GALIAZZI, M. do C.; SCHMIDT, E. B. Interpretações fenomenológicas e hermenêuticas a partir da análise textual discursiva: a compreensão em pesquisas na educação em ciências. Revista Pesquisa Qualitativa, São Paulo, v. 4, n. 6, p. 311-333, dezembro. 2016.

SOUSA, R. S. de, GALIAZZI, M. do C. Compreensões acerca da hermenêutica na análise textual discursiva: marcas teórico-metodológicas à investigação. Contexto \& Educação, Ijuí, v. 31, p. 33-55, setembro-dezembro. 2016.

TORRES, J. R. et al. Resignificação curricular: contribuições da investigação temática e da análise textual discursiva. Revista Brasileira de Pesquisa em Educação em Ciências, São Paulo, v. 8, n. 2, p. 1-13. 2008.

Recebido em: 30 de outubro de 2020 .

Aceito em: 21 de novembro de 2020. 